\title{
Hair cannabinoid concentrations in emergency patients with cannabis hyperemesis syndrome
}

\author{
Khala Albert, MD, MSc*; Marco L.A. Sivilotti, MD, MSc* ${ }^{* \neq}$; Joey Gareri, PhD ${ }^{\S}$; Andrew Day, MSc*; \\ Aaron J. Ruberto, MD*; Lawrence C. Hookey, MDף
}

\begin{abstract}
CLINICIAN'S CAPSULE
What is known about the topic?

Heavy users of cannabis increasingly present to the emergency department (ED) with unremitting vomiting, yet the precise cause of hyperemesis cannabis remains unknown.

What did this study ask?

Using hair to quantify longer-term exposure, do hyperemesis cannabis cases differ from other users with regards to their phytocannabinoid exposure profile?

What did this study find?

Cases and controls including ED patients with visits unrelated to cannabis had comparably high $\Delta^{9}$-tetrahydrocannabinol (and low cannabidiol) hair concentrations.

Why does this study matter to clinicians?

In counselling patients with hyperemesis cannabis, clinicians should highlight the uncertainties of surrounding exposure and recommend drug-free intervals or abstinence.
\end{abstract}

\section{ABSTRACT}

Objectives: Cannabis hyperemesis syndrome is characterized by bouts of protracted vomiting in regular users of cannabis. We wondered whether this poorly understood condition is idiosyncratic, like motion sickness or hyperemesis gravidarum, or the predictable dose-response effect of prolonged heavy use.

Methods: Adults with an emergency department visit diagnosed as cannabis hyperemesis syndrome, near-daily use of cannabis for $\geq 6$ months, and $\geq 2$ episodes of severe vomiting in the previous year were age- and sex-matched to two control groups: RU controls (recreational users without vomiting), and ED controls (patients in the emergency department for an unrelated condition). $\Delta^{9}$-Tetrahydrocannabinol (THC), cannabinol (CBN), cannabidiol, and 11-nor-9-carboxy-THC concentrations in scalp hair were compared for subjects with positive urine THC.

Results: We obtained satisfactory hair samples from 46 subjects with positive urine THC: 16 cases (age $26.8 \pm 9.2$ years; $69 \%$ male), $16 \mathrm{RU}$ controls and 14 ED controls. Hair cannabinoid concentrations were similar between all three groups (e.g. cases THC 220 [median; IQR 100,730] pg/mg hair, RU controls $150[71,320]$ and ED controls $270[120,560])$. Only the THC:CBN ratio was different between groups, with a 2.6 -fold $(95 \% \mathrm{Cl}$ $1.3,5.7)$ lower age- and sex-adjusted ratio in cases than $\mathrm{RU}$ controls. Hair cannabidiol concentrations were often unquantifiably low in all subjects.

Conclusions: Similar hair cannabinoid concentrations in recreational users with and without hyperemesis suggest that heavy use is necessary but not sufficient for hyperemesis cannabis. Our results underline the high prevalence of chronic heavy cannabis use in emergency department patients and our limited understanding of this plant's adverse effects.

\section{RÉSUMÉ}

Objectif: Le syndrome d'hyperémèse cannabique se caractérise par des accès prolongés de vomissements chez les grands consommateurs de cannabis. La question était donc de savoir si ce trouble, peu compris encore, relève d'un état idiosyncrasique, comme le mal des transports ou l'hyperémèse gravidique, ou d'un effet de type dose-réponse prévisible chez les grands consommateurs de cannabis.

Méthode: Des adultes chez qui un diagnostic de syndrome d'hyperémèse cannabique a été posé au service des urgences (SU), qui faisaient un usage presque quotidien du cannabis depuis $\geq 6$ mois et qui ont connu $\geq 2$ épisodes de vomissements importants au cours de l'année précédente ont été appariés à deux groupes témoins selon l'âge et le sexe : des témoins faisant un usage récréatif du cannabis, sans vomisse-

From Department of *Emergency Medicine, Queen's University, Kingston ON; †Department of Biomedical \& Molecular Sciences, Queen's University, Kingston, ON; ¥Ontario Poison Centre, Hospital for Sick Children, Toronto ON; §Independent Scientist; and the ๆDepartment of Medicine, Queen's University, Kingston, ON.

Correspondence to: Dr. Marco Sivilotti, Department of Emergency Medicine, Queen's University, 76 Stuart Street, Kingston, ON K7L 2V7; Email: marco.sivilotti@queensu.ca

(C) Canadian Association of Emergency Physicians 
ments (UR) et des témoins traités au SU (examinés pour des troubles non connexes). La teneur des cheveux en $\Delta^{9}$-tétrahydrocannabinol (THC), en cannabinol (CBN), en cannabidiol et en 11-nor-9-carboxy-THC a été comparée chez les sujets ayant obtenu des résultats positifs à l'égard du THC urinaire.

Résultats: Des échantillons satisfaisants de cheveux ont été prélevés chez 46 sujets ayant obtenu des résultats positifs à l'égard du THC urinaire : 16 cas (âge : 26,8 $\pm 9,2$ ans; sexe masculin : $69 \%$ ), 16 témoins UR et 14 témoins SU. La teneur des cheveux en cannabinoïdes était comparable dans les trois groupes (cas : THC : $220 \mathrm{pg} / \mathrm{mg}$ de cheveux [médiane; écart interquartile : 100-730]; témoins UR : 150 [71-320] et témoins SU : 270 [120-560]). Seul le rapport THC/CBN différait entre les groupes : il était 2,6 fois (IC à $95 \%: 1,3-5,7)$ inférieur dans les cas (rapport rajusté selon l'âge et le sexe) que chez les témoins UR. La teneur des cheveux en cannabidiol était souvent non quantifiable, et ce, chez tous les sujets.

Conclusion: Le fait que la teneur des cheveux en cannabinoïdes était comparable chez les utilisateurs faisant un usage récréatif du cannabis, tant chez ceux qui souffraient d'hyperémèse que chez ceux qui en étaient exempts, donne à penser qu'il y a un usage nécessairement abusif de la drogue mais non suffisant pour causer I'hyperémèse cannabique. Les résultats font ressortir la forte prévalence d'un usage excessif et prolongé du cannabis chez les patients traités au SU et le peu de connaissances que la communauté médicale a des effets indésirables de cette plante.

Keywords: Cannabinoid, cannabinoid hyperemesis syndrome, cannabis, cyclic vomiting, marijuana abuse, vomiting

\section{INTRODUCTION}

Little is known about cannabis (or "cannabinoid") hyperemesis syndrome, a newly recognized condition in which frequent cannabis users experience bouts of protracted vomiting. ${ }^{1-4}$ Now a leading cause of vomiting in emergency patients, ${ }^{1-3,5}$ its cause remains unknown. Is it merely the predictable result of accumulated exposure to increasingly potent cannabis, or poor quality/contaminated plant product, or an idiosyncratic reaction in a vulnerable subset like other episodic vomiting conditions (e.g., hyperemesis gravidarum)? ${ }^{1,4,6}$

To quantify the average exposure to cannabis over many weeks, we collected hair from patients being interviewed as part of a larger case-control study. ${ }^{7}$ We wondered whether emergency department (ED) patients with cannabis hyperemesis syndrome (cases) had higher concentrations of the four principal phytocannabinoids detectable in hair, as compared with recreational users without hyperemesis (controls).

\section{METHODS}

We approached consecutive eligible adult cases within two weeks of their index emergency visit. The case inclusion criteria were: chief complaint of vomiting, working diagnosis of cannabis hyperemesis syndrome, $\geq 2$ episodes of severe vomiting in the prior year, and $\geq 3$ days/week of cannabis use for $\geq 6$ months. We excluded current synthetic cannabinoid or chronic opioid users and acute overdoses of drugs including ethanol. Cases were matched by age and sex to: 1) recreational user (RU) controls who were recreational cannabis users without hyperemesis; and 2) ED controls who comprised the general emergency patient population, irrespective of cannabis use. Subjects provided written informed consent, and the institutional research ethics board approved this research.

We targeted a one-month interval from the index visit to the standardized interview, given the lag before new hair appears above the scalp. ${ }^{8}$ During the interview, we obtained urine and two samples of approximately 75 strands of hair cut from the scalp vertex. Hair samples were batch analyzed at an independent laboratory blinded to subject information (Appendix A). For the primary analysis, we retained only subjects who reported ongoing, recent use and whose urine immunoassay (Triage TM TOX 11; Alere, Waltham MA) was positive for $\Delta^{9}$-tetrahydrocannabinol (THC; threshold $50 \mathrm{ng} / \mathrm{mL}$ ).

\section{RESULTS}

The parent study met its target enrolment of 20 cases; four were interviewed more than a month after their last cannabis use and had negative urine THC. Sixteen of the $22(73 \%)$ RU controls and 14 of the $39(36 \%)$ ED controls had positive urine THC corroborating recent cannabis use and, thus, met the criteria for the analytical study. Hair and urine were harvested 29 days 
(median; interquartile range [IQR] 19,65) after the index visit (Supplementary Figure 1).

Cases were mostly men in the third or fourth decade of life who reported daily use of cannabis, averaging 7 (IQR 3.5, 11) g/week (Supplementary Table 1). The RU and ED controls with positive urine THC reported similarly frequent and heavy use, at 5 (IQR $1.5,8.3$ ) g/ week and 5.8 (IQR 2.6, 8.1) g/week, respectively. Testing the hair for cannabinoids, opiates, cocaine, or amphetamines was highly concordant with the urine, and hair cannabinoid concentrations correlated moderately with the subjects' self-reported weekly cannabis consumption (Figure Supplementary 2).

In the primary analysis, THC and cannabinol (CBN) concentrations demonstrated considerable overlap between cases and controls (Figure 1), but cannabidiol (CBD) and 11-nor-9-carboxy-THC (THC$\mathrm{COOH})$ were often below the limit of quantification (Supplementary Table 2). Adjusted for age and sex, there were only small and statistically insignificant differences between the groups with regards to hair cannabinoid concentrations (Supplementary Table 3). The THC: CBN ratio was 2.6 fold (95\% confidence interval [CI] 1.3-5.7) lower in the cases than the RU controls, mostly because of higher CBN concentrations in the cases yet was similar in the cases vs. the ED controls.

To corroborate self-reported abstinence and to assess the potential for surface deposition from recent smoking and/or drug handling, we examined the persistence over time of hair THC and CBN concentrations among all enrolled patients, including those with negative urine THC. Hair cannabinoid concentrations decreased but remained quantifiable among patients who had used during the previous month but became mostly undetectable when abstinent for two months or longer (Figure Supplementary 3).

\section{DISCUSSION}

One might assume that the remarkable increase in ED patients with hyperemesis cannabis is because of both the increasing potency of cannabis and its increasingly heavy use following broad societal normalization. If so, one would expect much higher concentrations of phytocannabinoids in the hair of patients with cannabis hyperemesis syndrome. Our findings run counter to this assumption. Instead, the wide overlap in hair concentrations between cases and controls suggests a more idiosyncratic mechanism, perhaps akin to hyperemesis gravidarum, a different pathophysiologic cause than the principal cannabinoids, or an episodic trigger that remains to be identified. Accordingly, the popular term, "cannabinoid hyperemesis syndrome," seems inappropriately specific to us and others.

These hair findings also demonstrate that heavy cannabis use is necessary, but not sufficient, for developing hyperemesis. Hair concentrations of THC and CBN were comparable to those of other studies involving heavy daily users. ${ }^{10-12}$ These findings are particularly relevant for the emergency physician when counselling these patients who seek credible information at a teachable moment. While awareness of this syndrome is slowly increasing among recreational users, patients may be reluctant to accept recommendations for abstinence, given their seemingly unaffected peers. Physicians, in turn, are limited by the largely anecdotal evidence base to the disorder.

Our findings are also remarkable for two other observations: the comparably high hair cannabinoid concentrations in one-third of young patients being seen in the $\mathrm{ED}$ for unrelated reasons and the extremely low CBD concentrations relative to THC and CBN, as compared with older studies. ${ }^{10}$ The first observation demonstrates that many young men and women being seen in our ED are heavy, daily users of cannabis. The second confirms both a marked increase in THC and decrease in CBD in recreational cannabis over the last two decades. Both changes are equally concerning, as CBD is believed to modulate the other adverse effects of THC. ${ }^{13-16}$

We doubt that an unrelated noxious contaminant or adulterant is responsible as in the apocryphal "bad batch theory." The well-known acute effects of cannabis on appetite and nausea implicate the phytocannabinoids themselves by lex parsimoniae. Cannabinoids are highly lipophilic and accumulate in peripheral fat stores with heavy use. We speculate that some emetogenic cannabinoids are released as these stores are mobilized during fasting, resulting in anorexia, vomiting, and further ketosis, releasing yet more cannabinoids from the peripheral stores. The brief respite reportedly afforded by a hot shower may be the result of reduced thermogenesis and adipose tissue catabolism, slowing this cycle. For this reason, we recommend that patients with ketosis and hyperemesis receive dextrose-containing fluids and warm blankets, in addition to crystalloids.

There were limitations related to any hair analysis. Drugs can be incorporated into hair through multiple routes 


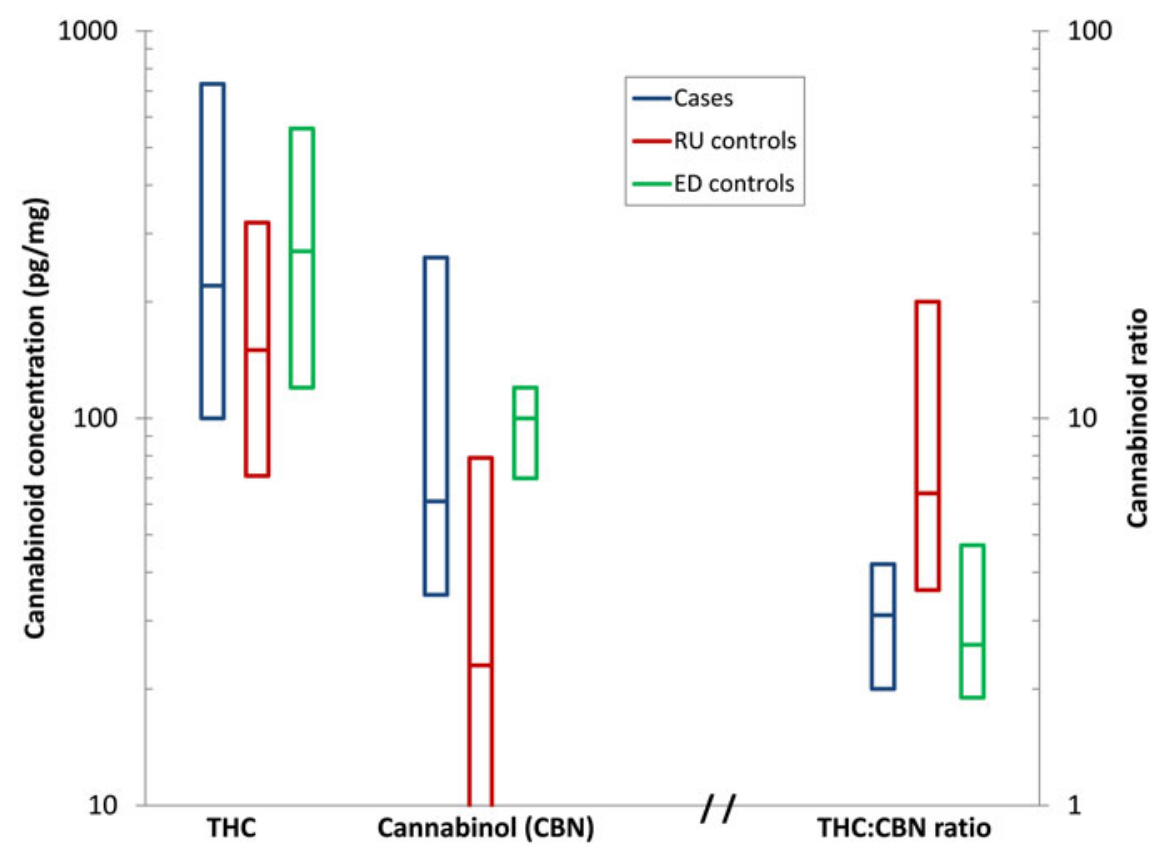

Figure 1. Median and IQR hair $\Delta^{9}-\mathrm{THC}$ and cannabinol (CBN) concentrations and their ratio between cases with hyperemesis cannabis, recreational users without vomiting (RU controls), and ED patients seen for unrelated conditions (ED controls), each of whom had positive urine immunoassay and admitted to recent cannabis use.

including sweat, sebum, and smoke deposition. ${ }^{17,18}$ While the segment analyzed reflects approximately two months of hair growth and a lag of approximately one month from hair formation, surface deposition despite in vivo and ex vivo washing shortens these time windows. If patients with hyperemesis were prone to high peaks then troughs from binges, followed by abstinence, their average would resemble the controls with more moderate but sustained use. CBD and THC-COOH are often below the limit of quantification, even in heavy users, ${ }^{11,12}$ precluding our ability to compare these cannabinoids or their exact ratios between the groups.

\section{CONCLUSIONS}

In summary, patients with cannabis hyperemesis syndrome who were seen in the ED have comparable hair cannabinoid concentrations relative to their peers without hyperemesis. These non-intuitive findings underline our limited understanding of the effects of chronic heavy cannabis use, including the role of specific phytocannabinoids in cannabis hyperemesis syndrome. This uncertainty, combined with the high prevalence of heavy use in the general ED population, lends strong support to public health initiatives intended to discourage excessive use and to countervail renewed enthusiasm for the benefits of cannabis.

Supplementary material: The supplementary material for this article can be found at https://doi.org/10.1017/cem.2018.479.

Acknowledgements: Presented at the Canadian Association of Emergency Physicians Annual Meeting, Whistler BC, June 2017. KA and MLAS conceived the study and designed it with $\mathrm{AD}$ and $\mathrm{LCH}$. KA recruited subjects, conducted the interviews, obtained the hair and urine samples under the supervision of MLAS, and managed the data. JG provided technical expertise regarding the hair analyses and their interpretation. $\mathrm{AD}$ provided statistical advice and analyzed the data. MLAS drafted and took responsibility for the manuscript as a whole, and all authors contributed substantially to its revision. This research received no specific grant from any funding agency, commercial, or not-for-profit sectors.

Competing interests: None.

\section{REFERENCES}

1. Sorensen CJ, DeSanto K, Borgelt L, Phillips KT, Monte AA. Cannabinoid hyperemesis syndrome: diagnosis, pathophysiology, and treatment-a systematic review. 7 Med Toxicol 2017;13(1):71-87.

2. Kim HS, Anderson JD, Saghafi O, Heard KJ, Monte AA. Cyclic vomiting presentations following marijuana liberalization in Colorado. Acad Emerg Med 2015;22(6):694-9. 
3. Habboushe J, Rubin A, Liu H, Hoffman RS. The prevalence of cannabinoid hyperemesis syndrome among regular marijuana smokers in an urban public hospital. Basic Clin Pharmacol Toxicol 2018;122(6):660-2.

4. Richards JR, Gordon BK, Danielson AR, Moulin AK. Pharmacologic treatment of cannabinoid hyperemesis syndrome: a systematic review. Pharmacotherapy 2017;37(6):725-34.

5. Hernandez JM, Paty J, Price IM. Cannabinoid hyperemesis syndrome presentation to the emergency department: A twoyear multicentre retrospective chart review in a major urban area. C7EM. 2017;20(4):550-5.

6. Richards JR. Cannabinoid hyperemesis syndrome: A disorder of the HPA axis and sympathetic nervous system? Med Hypotheses 2017;103:90-5.

7. Albert K. Cannabinoid hyperemesis syndrome in a Canadian emergency department: a case-control study (MPH thesis dissertation); London School of Hygiene and Tropical Medicine, 2017.

8. Pragst F, Balikova MA. State of the art in hair analysis for detection of drug and alcohol abuse. Clin Chim Acta 2006;370(1-2):17-49.

9. Dezieck L, Hafez Z, Conicella A, et al. Resolution of cannabis hyperemesis syndrome with topical capsaicin in the emergency department: a case series. Clin Toxicol (Phila) 2017;55 (8):908-13.

10. Skopp G, Strohbeck-Kuehner P, Mann K, Hermann D. Deposition of cannabinoids in hair after long-term use of cannabis. Forensic Sci Int 2007;170(1):46-50.
11. Huestis MA, Gustafson RA, Moolchan ET, et al. Cannabinoid concentrations in hair from documented cannabis users. Forensic Sci Int 2007;169(2-3):129-36.

12. Taylor M, Lees R, Henderson G, et al. Comparison of cannabinoids in hair with self-reported cannabis consumption in heavy, light and non-cannabis users. Drug Alcobol Rev 2017;36(2):220-6.

13. Potter DJ, Hammond K, Tuffnell S, Walker C, Di Forti M. Potency of $\Delta^{9}$-tetrahydrocannabinol and other cannabinoids in cannabis in England in 2016: implications for public health and pharmacology. Drug Test Anal 2018;10(4):628-35.

14. Dujourdy L, Besacier F. A study of cannabis potency in France over a 25 years period (1992-2016). Forensic Sci Int 2017;272:72-80.

15. ElSohly MA, Mehmedic Z, Foster S, et al. Changes in Cannabis Potency Over the last 2 decades (1995-2014): analysis of current data in the United States. Biol Psychiatry 2016;79 (7):613-9.

16. Freeman TP, van der Pol $P$, Kuijpers $W$, et al. Changes in cannabis potency and first-time admissions to drug treatment: a 16-year study in the Netherlands. Psychol Med 2018;48(14):2346-52.

17. Cooper GA, Kronstrand R, Kintz P; Society of Hair Testing. Society of Hair Testing guidelines for drug testing in hair. Forensic Sci Int 2012;218(1-3):20-4.

18. Moosmann B, Roth N, Auwärter V. Hair analysis for THCA-A, THC and CBN after passive in vivo exposure to marijuana smoke. Drug Test Anal 2014;6(1-2):119-25. 